\title{
Secured Smart E-Vehicle Tracking and Calamity Detection System Using Cloud- A Review

\author{
${ }^{*}$ Mohammad Ausef Umair, ${ }^{2}$ Rutuja Kharkar, ${ }^{3}$ Mohammed Adil Khan, ${ }^{4}$ Ankur Bobade, ${ }^{5}$ Munmun \\ Ghoshal, ${ }^{6}$ Meeta Bakuli \\ Pune, India \\ *Email: ausefumair1996@gmail.com
} \\ ${ }^{1-6}$ Department of Electronics and Telecommunication, G. H. Raisoni College of Engineering and Management
}

Received: $17^{\text {th }}$ January 2019, Accepted: $13^{\text {th }}$ February 2019, Published: $3^{\text {th }}$ June $_{2019}$

\begin{abstract}
A capable automobile safety arrangement is put into action for calamity detection, by means of an embedded architecture having a Global Positioning System (GPS), Wi-Fi Module and cloud. Now a day's vehicle population is growing exponentially, so is the number of thefts and accident associated with vehicles and in most cases, the owner could retrieve his/her vehicle from the location. With more than one billion vehicles in use in the world, a smart e-vehicle tracking and calamity detection system using cloud is always a boon to the owners. The system sends a predefined message if theft and accident happens. The user can track the exact location of their vehicle with the help of Google earth on an android mobile application using GPS location identifier, The object's present position is find out and send, along with other important parameter conveyed by vehicle delta ports via cloud server with the help of Wi-Fi module which is associated to computer or smart phone.

Since the key intermediate of communication is Internet the term IOT is employed here. The proprietor of the vehicle has an option of disconnection the fuel connection to the engine if he/she wants to take instantaneous action against the attacker. Vehicle also contains the tracking feature, tracking application and will get image of thief driving the vehicle. The most significant feature of this paper is calamity detection. It follows the same method as in melt recognition i.e. when calamity dose takes place the accelerometer reading and Piezoelectric sensor reading with activate the system start sending coordinates of the calamity location to the law enforcement authorities ,hospitals \& family member's so they can take an immediate action.
\end{abstract}

Keywords

Tracking Structure, Global System for Mobile Communication, Automobile Tracking, Internet of Things, Calamity Detection, Raspberry Pi.

\section{Introduction}

As India is developing rapidly, an automobile Industry is growing and there is in-crease in use of automobiles as the population of India is very high. Due to this the accidents and larceny are happening. To get reed of the current concerns we have to developing the satcom technology is simple to recognize the location of automobile. Automobile tracking technologies now are part of common person's amenities. Now a day's Gps is used in automobiles also previously it was only used by ships, airplanes and military. In India, generally the GPS in the automobiles is used for navigation purpose and it was only present in costly automobiles. IoT based technology is now important, with Gps and IoT we can track the vehicle in real time basis which will help to find the vehicle if stolen easily or calamity happens to it. The internet of things is a structure of interconnected computing devices, digital \& mechanical machines, objects, animals or humans that are offered with unique identifiers (UIDs) \& the capability to relocate data over a network with no requiring human-human or human-computer interaction, it enable all these parameters to gather $\&$ exchange data. This will directly integrate with physical worlds and computer base systems which will increase accuracy, efficiency and economic benefits. At present, not all devices are connected to internet by IoT embedded technology it can happens. This will help to communication between machines easy even they are place long from each other. The IoT technology will help to build smart Cities in which all physical aspects can be converted into digital.

\section{Literature Survey}

A motorbike safety system to avoid robber from robbing the motorbike was well explained in this article [2]. Here microcontroller is used and was considered based on GSM Communication. The kit can be mounted at hidden place in the motorbike. Alert message will be send to the microcontroller in case of pressing the paddle or starting an engine with no key or false key. 
A system based on GSM unit will be more effective than a regular safety unit. This concept is well explained in this article [3] which uses embedded interface.

The school bus tracking \& monitoring system from any geological location with advanced approach is well elaborated in this article [4]. They in fact use innovative approach based on Embedded Linux board specifically Raspberry Pi along with some high ends attributes of database storing at actual instance. For automobile tracking and monitoring unit the anticipated system works on GPS \& GSM. SIM908 module consist of three most important modules specifically GPS, GPRS \& GSM are employee for this purpose

\section{System Development}

The hardware setup consists of Raspberry Pi 3, GPS Module, Inductive Proximity Sensor, 5 V Relay with driver circuit, Camera module, solenoid valve, monitor, Key-board, mouse. Cloud used here is 'Weaved'. Power supply of $5 \mathrm{~V}$ is Given to the system either through adapter or using transformer circuits. structural design of the structure development is as described in below fig. 1

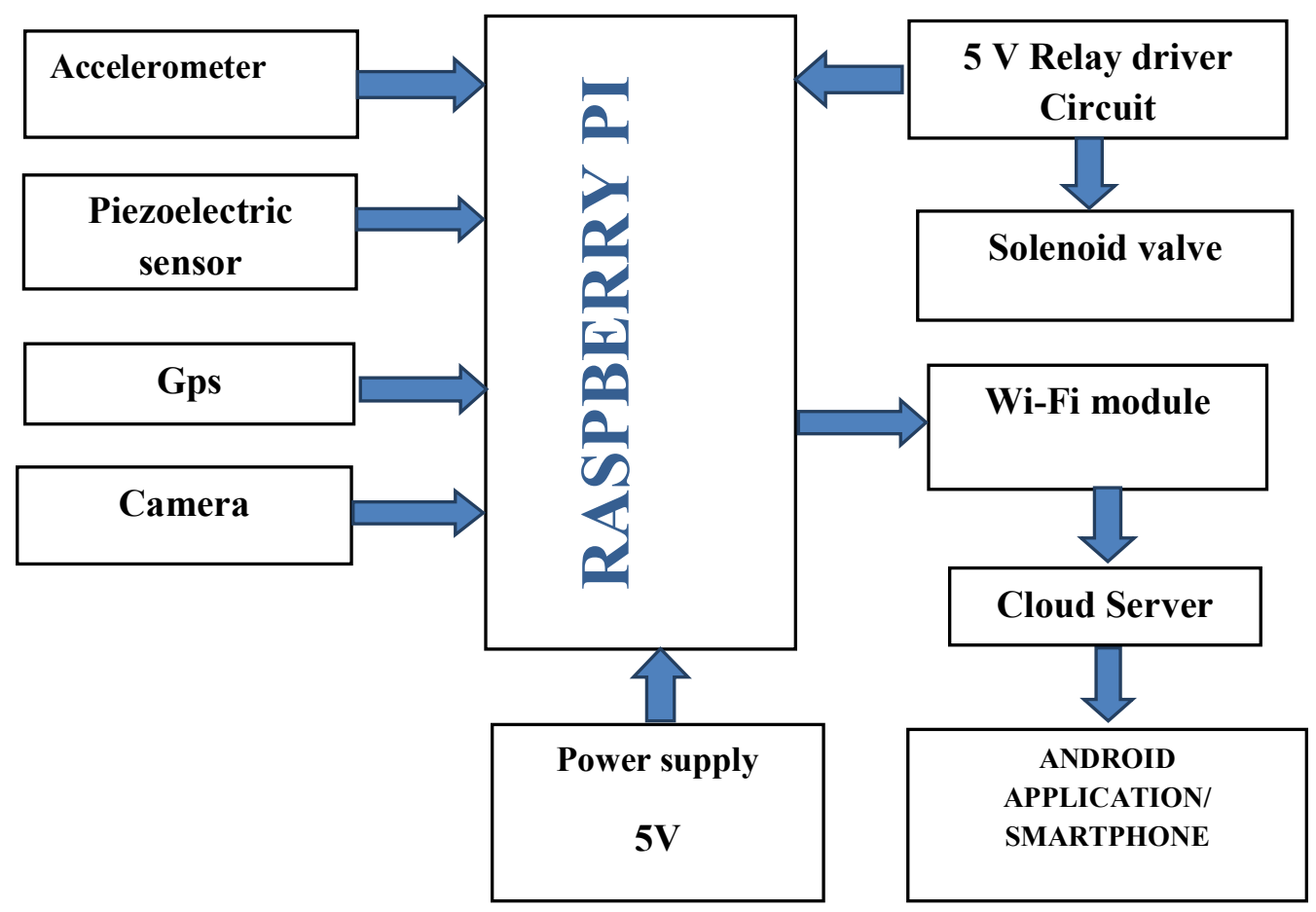

Supply System

Figure 1: Block Diagram of System

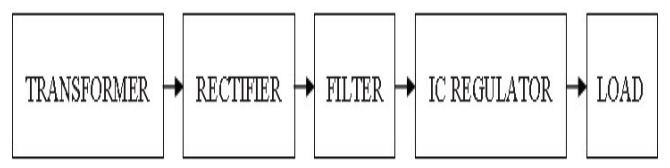

Figure 2: Block Diagram of Supply Circuit

A $220 \mathrm{~V} 50 \mathrm{~Hz}$ AC voltage is applied to the transformer, which step down AC voltage to the level of the desired dc output. A simple capacitor filter is used to produce a dc voltage initially and then given to a full wave rectifier circuit to achieve rectified output. This resulting dc voltage consists of ripples which are also called as ac voltage deviation.

IC regulator circuit eliminates the ripples \& keeps maintaining the equivalent dc value even if the dc input voltage varies, which is further excited by some load. 


\begin{tabular}{|c|c|c|c|}
\hline Specification & Raspberry Pi & Raspberry Pi 2 & Raspberry Pi 3 \\
\hline SoC Type & BCM 2835 & BCM 2836 & BCM 2837 \\
\hline Core Type & ARM1176JZF-S & ARM Cortex a7 & ARM Cortex a53 \\
\hline No. of Cores & 1 & 4 & 4 \\
\hline CPU Clock & $1.2 \mathrm{GHz}$ & $900 \mathrm{MHz}$ & $700 \mathrm{MHz}$ \\
\hline RAM & $1 \mathrm{~GB}$ & $1 \mathrm{~GB}$ & $512 \mathrm{MB}$ \\
\hline USB Ports & 4 & 2 & 1 \\
\hline $\mathrm{WiFi}$ & 802.11 & Not available & Not available \\
\hline Specification & Raspberry Pi & Raspberry Pi 2 & Raspberry Pi 3 \\
\hline SoC Type & BCM 2835 & BCM 2836 & BCM 2837 \\
\hline Core Type & ARM1176JZF- S & ARM Cortex a7 & ARM Cortex a53 \\
\hline No. of Cores & 1 & 4 & 4 \\
\hline CPU Clock & $1.2 \mathrm{GHz}$ & $900 \mathrm{MHz}$ & $700 \mathrm{MHz}$ \\
\hline RAM & $1 \mathrm{~GB}$ & $1 \mathrm{~GB}$ & $512 \mathrm{MB}$ \\
\hline USB Ports & 4 & 2 & 1 \\
\hline $\mathrm{WiFi}$ & 802.11 & Not available & Not available \\
\hline
\end{tabular}

Table 1: Comparison of Raspberry Pi Versions. 


\section{System Flow Chart}

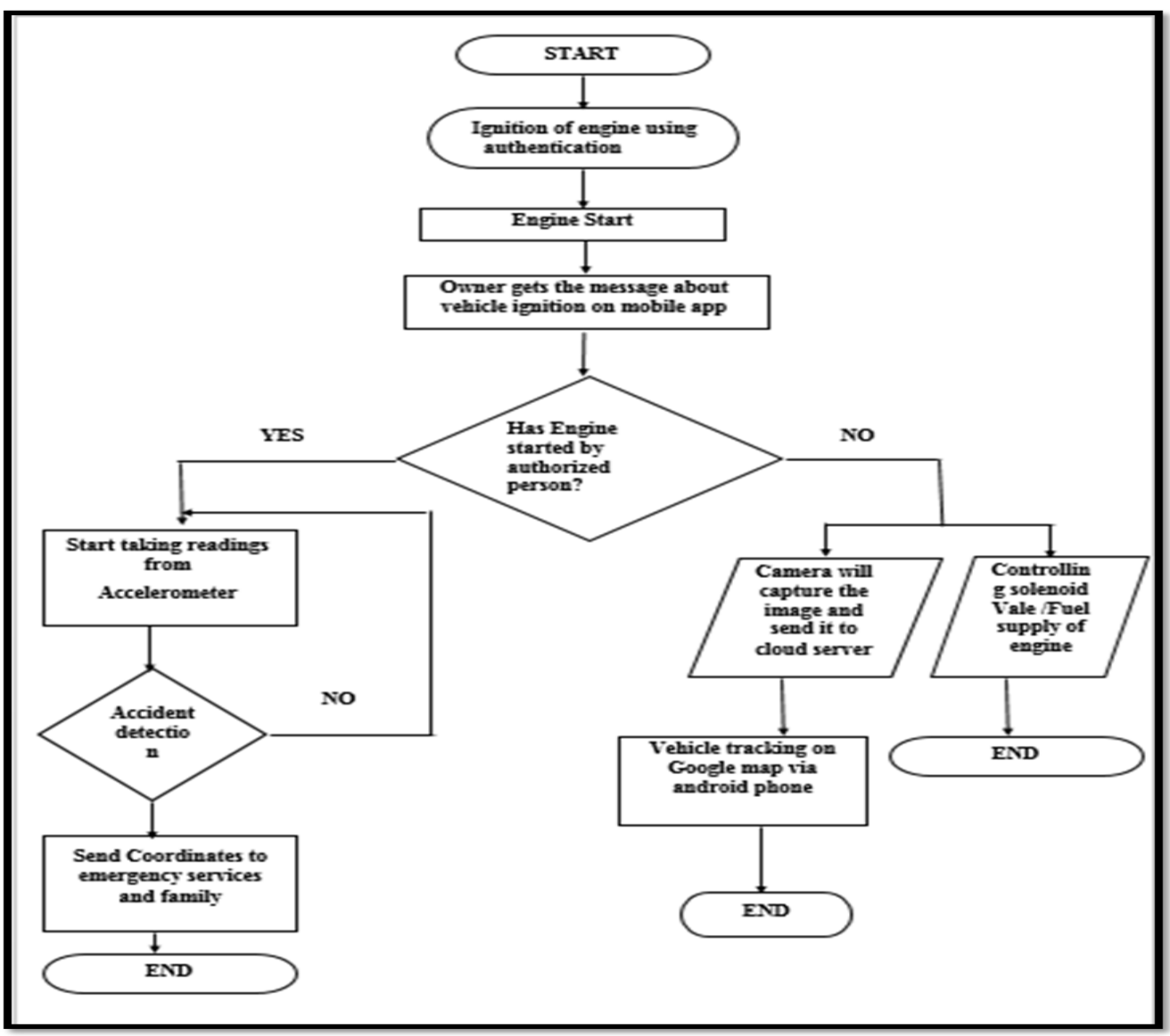

\section{ARM Cortex A53}

ARM Cortex A53 supports 32-bit and 64-bit instruction sets effortlessly. To achieve this performance it uses extremely capable 8 stage in order pipeline architecture with superior fetch and data access techniques. Thus it is suitable for entry level smart phones. It also have high core density which delivers collectively better performance, which is popular for base station and networking blueprints.

\section{GPS Antenna}

The GPS antenna is not as similar to regular ordinary antenna which is available in market. i.e it would not only make use of the $1575.42 \mathrm{MHz}$ (L1 frequency), but it also make use of the $1176.45 \mathrm{MHz}$ (L5 frequency) to be introduced in the future.

\section{Accelerometer unit}

The variation in acceleration readings in $\mathrm{x}, \mathrm{y} \& \mathrm{z}$ axis is measured which gives analogous electrical voltage indicator to the variation in the assumed axes. This unit is activated in case of occurrence of calamity.

\section{Relay Driver Circuit}

An electrically activated switch is known as a relay. a magnetic zone is created when the current passing from the curl of the relay which draws in a device and vary the contacts of the switch. Relay have two switch points at which curl current can be on or off, thus they are called changeover switches. It enables a circuit to switch to alternative circuit which is completely isolated from the primary circuit.

\section{Solenoid Valve}

A solenoid valve can be said as an electromechanically operated valve. An electric flow over a solenoid is supervised by a valve, the stream is kept on or off in the circumstance of a two port valve. The outpouring is switch between the two output ports in the circumstance of a three port valve.

\section{Camera Module}

The Camera Module can be utilized to take top quality video, and also catches photograph. Starters can easily use it but a lot of options are available for users that are advance in case you're hoping to extend your 
insight. There are bunches of accessible models online of individuals utilizing it for time-lapse, slow motion, and other video intelligence.

\section{Piezoelectric Sensor}

Piezoelectric sensors are versatile components for the estimation of different techniques. They are utilized for quality confirmation, process control, and for inventive work in different undertakings.

\section{Conclusion}

The proposed method has made great utilization of the IOT and Cloud processing for the better security purpose, yet this undertaking gives assurance just as aides in recognizing the unapproved client. A secret key ensured security framework is worked for empowering the start in vehicles. The proposed framework made incredible usage of Smartphone advancement by giving prosperity and secure passing by prepared segment of the cars from being stolen. A productive and practical framework has been made with great outcomes. The earlier strategies implemented for the insurance of the cars had been exorbitant and less.

\section{References}

1. Al-Taee, M.A., Khader, O.B., Al-Saber, N.A.: Remote Monitoring of Vehicle Diagnostics and Location Using a Smart Box with Global Positioning System and General Packet Radio Service. In: IEEE International Conference on Computer Systems and Applications, pp. 385-388. IEEE Press, Amman (2007).

2. M. A. Mohd Nasir, W. Mansor "GSM based motorcycle security system" IEEE Control and System Graduate Research Colloquium, IEEE Explorer 18 August 2011.

3. Vivek Kumar Sehgal, Mudit Singhal, Bhart Mangla, Sudeep Singh and Shivani Kulshrestha "An Embedded Interface for GSM Based Car Security System" Fourth International Conference on Computational Intelligence, Communication Systems and Networks, CICSyN 2012, Phuket, Thailand, pp.9-13, July 24-26, 2012.

4. Prashant A. Shinde and Professor Mr. Y. B. Mane "Design and Development of Vehicular Monitoring, Tracking and Accident Identification System using Raspberry Pi” IJERT Vol. 5 Issue 11, November-2016, pg. $150-153$.

5. Ms. C.Aruna Ms. A.Godawari “An Iot Based Anti-Theft Health Monitoring” .Ijmtarc - Volume - Iv Vehicle Tracking \& Accident Prevention By Vehicle Issue - 16 - Dec 2016.

6. Dr. Santhoshi Rani M.Tech, PG Student "Raspberry Pi Based Vehicle Tracking And Security System For Real Time Applications” IJCSMC, Vol. 5, Issue. 7, July 2016, pg.387 - 393.

7. SeokJu Lee; Tewolde, G.; Jaerock Kwon, "Design and implementation of vehicle tracking system using GPS/GSM/GPRS technology and smartphone application," Internet of Things (WF-IoT), 2014 IEEE World Forum on , vol., no., pp.353,358, 6-8 March 2014.

8. M. S. Joshi and D. V. Mahajan, "Arm 7 based theft control, accident detection and vehicle positioning system," International Journal of Innovative Technology and Exploring Engg, vol. 4, no. 2, pp. 29-31, July2014.

9. M. A. A. Khedher, "Hybrid GPS-GSM localization of automobile tracking system," International Journal of Computer Science and Information Technology, vol. 3, no. 6, pp. 75-85, Dec 2011.

10. J. R. Shaikh and S. M. Kate, "Arm7 based smart car security system, International Journal of Engineering Trends and Technology, vol. 3, no. 2, pp. 210-212, March 2012.

11. J. M. Hu, J. Li, and G. H. Li, “Automobile anti-theft system based on GSM and GPS module," presented at the Fifth International Conference on Intelligent Networks and Intelligent Systems, Tianjin, China, November 13, 2012.

12. Saed Tarapiah, Shadi Atalla, Basim Alsayid "Smart on-board transportation management system GeoCasting featured," Computer Applications and Information Systems (WCCAIS), 2014 World Congress on, vol., no., pp.1,6, 17-19 Jan.2014. 